Marc-Philippe Weller

\title{
Die Vertragstreue
}

\author{
Vertragsbindung - Naturalerfüllungsgrundsatz - Leistungstreue
}

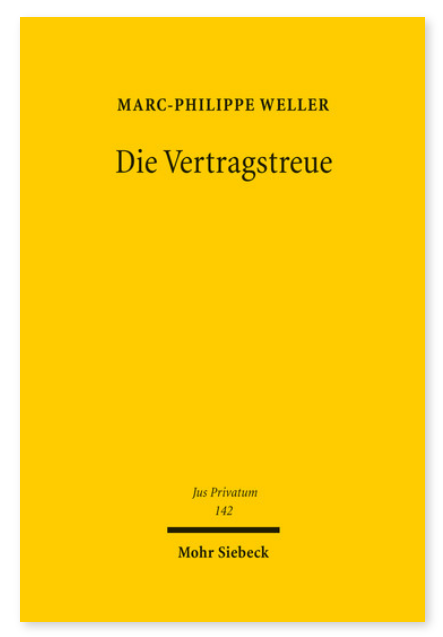

2009. XXXI, 633 Seiten. JusPriv 142

ISBN 978-3-16-151219-3

DOI 10.1628/978-3-16-151219-3

eBook PDF 159,00€
Der Grundsatz der Vertragstreue (pacta sunt servanda ), im Rechtsverkehr immer wieder angeführt, wurde durch die Schuldrechtsmodernisierung 2001 nachdrücklich gestärkt (»Recht zur zweiten Andienung«), jedoch immer noch nicht ausdrücklich kodifiziert.

Marc-Philippe Weller analysiert diesen Grundsatz rechtsdogmatisch. Er bezieht dabei auch die Rechtsvergleichung ( common law, Draft Common Frame of Reference ) und die Privatrechtsgeschichte mit ein und identifiziert drei Elemente der Vertragstreue: Die Vertragsbindung, den Naturalerfüllungsgrundsatz und die Leistungstreue. Alle drei Elemente werden gesondert untersucht und im BGB verortet. Dabei werden neue Zusammenhänge aufgezeigt: Der Vertragstreue wohnt in allen ihren Elementen nicht nur eine gläubiger-, sondern jeweils auch eine schuldnerbegünstigende Seite inne. Denn der Schuldner hat ein schadensersatzbewehrtes Recht, seine Leistung in Natur zu erbringen. Da der Naturalerfüllungsgrundsatz international betrachtet - nicht unumstritten ist, sondern mit dem Pekuniarerfüllungsprinzip (Schadensersatz statt der Leistung) konkurriert, hat sich der Autor zum Ziel gesetzt, die Legitimation der Naturalerfüllung sowie ihre - für die Privatrechtsordnung insgesamt - systembildende Funktion herauszuarbeiten. Insbesondere analysiert er die auf Savigny und Windscheid zurückgehende Struktur des Naturalerfüllungsanspruchs des Gläubigers ( 241 Abs. 1 BGB) und stellt sie dem im common law und in Einheitsprojekten vorherrschenden remedy -Konzept (Rechtsbehelfsmodell) gegenüber. Der Autor zeigt in diesem Zusammenhang die Vorzüge der Vertragsrechtsdogmatik des BGB auf.

Das Buch wurde im Oktober 2009 mit dem Helmut-Schippel-Preis der Deutschen Notarrechtlichen Vereinigung e.V. ausgezeichnet.

Marc-Philippe Weller ist Direktor am Institut für ausländisches und internationales Privat- und Wirtschaftsrecht der Universität Heidelberg.

Jetzt bestellen:

https://mohrsiebeck.com/buch/die-vertragstreue-9783161512193?no_cache=1

order@mohrsiebeck.com

Telefon: +49 (0)7071-923-17

Telefax: $+49(0) 7071-51104$ 